\title{
The strategic development for water loss prevention
}

\author{
Recep Kiliç ${ }^{1}$ (D) \\ Received: 6 September 2020 / Accepted: 28 October 2020 / Published online: 24 January 2021 \\ (c) The Author(s) 2021
}

\begin{abstract}
The population growth and urbanization have gained importance in the Water Resource Management (WRM) works. The classic approach in relation to the development of the water resources has lost its sustainability. Water has, therefore, become an important, but also becoming a scarce natural source due to the global warming and its climate change impacts end results. The major aim of WRM is to increase the Water Distribution Network (WDN) to keep water supply sustenance by decreasing the water demand. The new approaches in relation to the WRM should take into consideration in a more refined manner the supply-demand balance with the improvements in the WDN. Recently, water resources performance improvements have become one of the significant investment topics in Turkey. However, data from the Turkish Statistical Institute and any academic research in this field have shown that there is a water loss of around 50\% in the current water supply and distribution systems. In comparison to other developed countries, this loss is very high. It became, therefore, necessary that each Water Resources Administration should keep track on the costs, water leakage losses and the necessary technological investments. In the scope of this study, water loss levels reduction strategy possibilities are developed in the Sakarya City WDM system, Turkey. These strategies field applications have been presented in detail. Finally, the extent of accuracy in these strategies has been shown, which may provide guidance for other water administrations departments in the world.
\end{abstract}

Keywords Water Resource Management (WRM) · Water Distribution Network (WDN) · Domestic Water Supply and Distribution Network (DWSDN) · District Metered Areas (DMA) - Supervisor Control and Data Acquisition (SCADA) . Geographic Information System (GIS) · The Minimum Night Flow (MNF)

\section{Introduction}

As a result of urbanization, the local and central governments have made large investments for water supply in order to meet the demand in balance. The water loss within the Domestic Water Supply and Distribution Network (DWSDN) constitutes a huge problem in many countries around the globe. The huge investments and loss of domestic water, in the supply network, have brought drastic measures and investments in the water management system. Every Water Administration should, therefore, keep track on the economical consequences by keeping track on water losses, under the light of the recent technological developments and investments to reduce the costs of supply.

Recep Kiliç

recep.kilic@sakarya-saski.gov.tr

1 Sakarya Water and Sewerage Administration (SASKI), Kentpark, PK 144 Adapazarı, Sakarya, Turkey
In Turkey, the proportion of water loss within the DWSDN is high, whereby it is strongly recommended to keep track on this matter by water administration departments.

Recently, the supply and distribution of domestic water gained significant importance in order to decrease and manage water losses, whereby in 2014 the Ministry of Forestry and Water Affairs has released a rules and regulations guidance named "The management and Control of Supply and Distribution of Domestic Water within the Network" and in 2015 "Technical Procedure Communication." These guidances aim to decrease the water loss on the average down to $25 \%$.

Studies in water loss in relation to urbanization should be tracked and displayed in the Water Balance Table (Lambert et al. 1999; Farley and Liemberger 2005) by every Water Administration. This table will help to keep track on the water loss components whereby this table will at the same time help to choose the right direction in relation to those components. 
Even though the loss in water seems to be an issue of the local government, the details indicate that it is also affecting the central government expenditures economically. In Turkey, the local governments are accessing water by making use of water pumping sets and water supply stations. The loss of million cubic meters in domestic water within the DWSDN's causes to the pollution and to energy wastages. It is, therefore, necessary to pay attention to water losses, but also the energy wastage.

In the past view years, despite the effort for the water loss prevention, it was not possible to solve this issue, in general. Even though the necessary researches have been made in relation to the water loss, the necessary judgments have not been tackled sufficiently in the domestic government departments. In order to prevent the water loss, the Turkish Administration has kept statistics on the difference between the water input into the system and the billed consumption, which is necessary to decrease the difference significantly. In order to reach the former mentioned aim, the water supply into the DWSDN's have been measured and attention have been paid to the right water pressure. At the end, a comparison has been made between the water supply and the end bill for the consumption of the supplied water, which is necessary in order to take the right decision on the best suitable strategies development.

In order to decrease "real losses," the necessary attention should first be paid to the pressure management within the distribution network by means of the active leak control and the pipelines (if available) along with the speed in repair and the effort in quality improvements. In addition, the active decrease in water loss should be realized by stimulating an independent existence of large hydraulic Domestic Water Supply Networks within the 'District Meters Areas' (DMA) (Gomes et al. 2012a, b). The flow of water within the DMA should constantly be monitored, whereby the minimum flow should be measured every night. Apart from the measurements, the repair and renewal of the pipelines should also be considered. In addition, the DWSDN's should be transferred to the Geographic Information System (GIS). It is strongly recommended to make use of the Supervisor Control and Data Acquisition (SCADA) system in order to keep track on real-time control and on the necessary equipment.

The empirical estimates in the UARL formula are derived mostly from tests in district metered areas in England and Wales during the late 1990's. For example, the UARL of the main pipes is a combination of background leakage and leakage from reported and unreported breaks. All of these components are affected by network material and age. Further studies are needed to clarify whether the empirical parameters of the ILI formula are applicable to utilities with low connection densities and relatively young pipes.

It is clear that perceptual leakage targets are not very suitable, even when used internally at utilities, as the leakage percentage is a function of water use. Our results suggest that the ILI, even though it is theoretically more appropriate, is not a suitable indicator for setting leakage targets in Finland. Instead, in the absence of a suitable indicator, the utilities could be obligated to monitor leakage levels and formulate leakage management plans in the long term.

Decreasing the number in water loss by using the ILI and the Non-Revenue Water percentage, it is clear that a diversity in approach is needed. In the scope of this research, a method of calculation for the prevention of water loss has been developed within the DMA. As a result, a successful strategy has been created.

After the distribution network water loss levels are measured, apparent and real losses strategies must be initialized for the struggle. In order to fulfil the components successfully, the difficulties in the process should first be understood and then the necessary technical capacity should be developed. In order to realize the former, access to sufficient financial support should be realized for the renewal of the infrastructure, and strategical plan of each Water Administration for the decrease of water losses.

\section{Literature review}

Researches in this paper have taken into consideration the results of other related studies in the literature. In accordance with the mentioned studies, the following reasons have been presented briefly concerning the water loss problems.

- Leakage within the WDN (Samir et al. 2017)

- Leakage of water in the supply and reservoir network (Özdemir 2018)

- Leakage within the supply pipelines (Özdemir 2018)

- Illegal use of water by customer (Washali et al. 2020)

- Missing projects and the usage of unsuitable equipment

- Metering inaccuracies (Richards et al. 2010)

- The late repair of any breakdowns (Kanakoudis and Tolikas 2001)

- Unbilled water consumption by the fire station, in gardens, in parks, at religious facilities.

As a result of these reasons, water loss should be conducted by creating a strong team work and coordination within the water administration departments or centers. Subsequently, drastic savings can be achieved in the process from the water supply until the water consumption process (Karadirek 2016).

Administrations that have impacts and leading roles in the water management affairs should make use of the latest technologies (Muhammetoğlu and Muhammetoğlu 2017). The main factors in water management are productivity and the cost optimizations. It is unfortunately painful to 
say that those administrations facing with water loss are not paying enough attention to productivity (Ferrari and Savic 2015). A productive administration management should consist of a system that pays attention to strategies to combat with water losses (Adedeji et al. 2018) and their reduction to an acceptable level (Ahopelto and Vahala 2020). This should be the right strategy, which should easily be followed up by every administrational system.

The administration system should first measure the current water loss levels (Adedeji et al. 2018) and sum up the aims in relation to the acceptable level to reach water loss reduction. For this purpose, it is recommended to pay attention to the water loss causing components (Kanakoudis et al. 2015) as mentioned on the Standard Water Balance Table (Lambert et al. 1999; Farley and Liemberger 2005) along with the strategies with a low budget (Adedeji et al. 2017). Among some of the components there are eight main reasons that might be less costly than the other components (Kanakoudis and Tsitsifli 2009; Tabesh et al. 2009).

In general, profits can be obtained when a real loss (Özdemir 2018; Tabesh et al. 2009; Fontana et al. 2016) is determined and the necessary measures are taken which can be reflected to the costs for supply and operating processes. The reflection is risible once the costs start to decrease. The administrations' general profits is expected to increase once the water losses are fixed (Tabesh et al. 2009; Xin et al. 2014; Rizzo et al. n.d.). Furthermore, the administrations' primary aim should be to increase the profits and decrease the losses.

Moreover, the aim to lower the water loss levels should be determined by setting up a plan and applying it in practice. Plan setting is beneficial, but also costly at the same time. Consequently, administration should consider whether it is, in general, financially sustainable to bear the costs in the long run (Muhammetoğlu et al. 2018). It is really attractive that the strategies should be on ready, but in the later stage the process may slow down as there might be some budget cuts resulting from the strategies in unfortunate situations (Ociepa et al. 2019). To avoid the former, it is strongly recommended to set up pilot projects to develop the mentioned strategies. The pilot project stimulates application and testing the necessary components for the water loss reduction strategies (Cinal 2009). If the pilot project seems to be successful, then it would be easier to apply in a larger project by keeping easier track on the financial balance.

After fulfilment of the said procedures, the accuracy of the tests should be compared with the standardized components. The former can be tackled by using the International Water Association's (IWA) Infrastructure Leakage Index, Current Annual Real Losses (CARL) and Unavoidable Annual Real Losses (UARL) Loss as a great performance example (Lambert and Hirner 2000).
$\mathrm{CARL}=\mathrm{SIV}-\mathrm{UAC}-\mathrm{BAC}$

In the case the water System Input Volume (SIV) into the network in, Unbilled Authorized Consumption (UAC) for the administrations' own water consumption, and Billed Authorized Consumption (BAC) is the sold water; all in $\mathrm{m}^{3} /$ year. Hence, also $\mathrm{m}^{3} /$ year Inevitable Annual Real Loss (UARL) can be expressed as,

$\mathrm{UARL}=\left(18 \times L_{\mathrm{m}}+0.8 \times N_{\mathrm{c}}+25 \times L_{\mathrm{p}}\right) \times p$

where $L_{\mathrm{m}}$ is for the main supply length $(\mathrm{km}), L_{\mathrm{p}}$ is standing distance for the pipelines from the customers private land to the main meter in $(\mathrm{km}), N_{\mathrm{c}}$ is for the number of service connections, $p$ is for the average pressure (m). Finally, the Infrastructure Leakage Index can be expressed as follows.

$\mathrm{ILI}=\frac{\mathrm{CARL}}{\mathrm{UARL}}$

\section{Invisible water leakage determination on surface}

In general, the total water losses in the WDN are real losses (Washali et al. 2020). It takes time until the administration realizes the losses and repairs the leaks whereby the water loss volume increases (Hussein et al. 2017). It can take surprisingly weeks and years for underground leakages quantification, and therefore, water losses should be countered by water leakage strategies in addition to the water leakage areas determination (Yang et al. 2008) and the decrease in maintenance time.

In order for the administration to determine the different leakage types, the flow discharge, flow time, location determination and ALR procedures maintenance should be cared for along with the Real Volume Loss (Muhammetoğlu and Muhammetoğlu 2017). The kind of leakages within the WDN consists of notified and unnotified leakages in addition to the background leakages (those are small leakages, which are difficult to determine and expensive to maintain) (Adedeji et al. 2018; Xin et al. 2014).

The active leak control determination is a cost-effective, important and effective lifesaving method (Yang et al. 2008). In order to use this method effectively, the network hydraulics should be separated from each other in the District Metered Areas (DMA) (Farley and Liemberger 2005; Xin et al. 2014). As the DMA flow at the entrance is very sensitive, the measurements should be made with sensitive flow meters (Richards et al. 2010; Kara et al. 2015). Any leakages of the pipelines within the network could be determined earlier during the measurements as the flow starts to increase and exceeds pre-determined limits. The

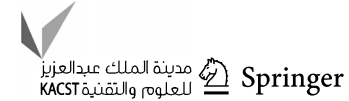


former should be done along with the minimum night flow measurements (Tabesh et al. 2009; García et al. 2006) and the net night flows (leakages). The increase in night flow shows the increase in leakages. It is strongly recommended to use acoustic methods in order to trace the right leaking pipeline(s).

\section{System entrance measurement}

The flow measurement within a WDN should start at the system's entrance (Washali et al. 2020; Kanakoudis et al. 2015; Kara et al. 2015), which stimulates the possibility to understand the features much better. The following hierarchy shows the way and procedure of the measurements:

- First of all, spring water is being measured until the entrance and exit of the water from reservoir, the entrance and exit of the treatment facility and the backwash flush (Kara et al. 2015).

- Water demineralization, at the entrance and exit of the water reservoir (Washali et al. 2020).

- At the entrance-exit of the water pump stations.

- At the geographic and hydraulic borders by measuring the region.

- Measurements in district metered areas (Washali et al. 2020; Kanakoudis et al. 2015; Kara et al. 2015).

- The placement of customers or commercial places.

The measurements within the scope of this study have started at the Sapanca Leak in the Province of Sakarya (Turkey). Here, the untreated water has been measured by attaching a flow meter at the exit of the pump station. At the first stage (Year 2009), flow meters have been mounted in areas, where the capacity of the water reservoir were above the level of $4000 \mathrm{~m}^{3}$ or areas where the water capacity of the water reservoir was below the level of $4000 \mathrm{~m}^{3}$ with a population density. In the scope of this stage, 7 (seven) flow meters have been mounted at the locations. Some of the mounted flow meters are currently in use.

\section{Distribution lines and digitation of the network}

As one can imagine, it is impossible to remember the WDN lines, locations and depths of the pipelines. As a result of fast urbanization and the density in substructure make it hard and almost impossible to keep track on the lines if the necessary information are not saved somewhere (Alici and Özaslan 2018). In the past, former workers have tried to transfer the necessary knowledge and experience regarding the substructure to the new starters. This should be avoided and digitized in order to keep fast track on any issue and to improve the performance of administration.
In such works, the importance of the Geographic Information Systems (GIS) has grown and the need has grown for digitation of the substructure (Keskin and Yllmaz 2005). Formerly, the necessary determinations have been made by keeping track on the investments in addition to a track on the economic lifetime and maintenance has been kept. From this information, it is obvious that digitation is an effective method to decrease the number of water losses (Alic1 and Özaslan 2018).

From this view, the WDN measurements should be digitized into the GIS, the water loss should be inspected via the system and the life time of the pipelines should be taken into consideration before the necessary decisions are being taken. Within GIS, every DMA area should have its own archive whereby the necessary information should be saved from field research until the measurements of pipelines, connection points, coordination, and length etc. Every detail like the brand, type, height, age and numbers of the networks should be saved as well (Alıcı and Özaslan 2018). This information is off importance to counter the water loss.

The necessary information form 2009 until today in relation to the district areas of Adapazar1, Erenler and Serdivan in Sakarya region are available. The network in these areas have been planned, coordinated and digitized. The necessary auction information and the recent constructions (renewals excluded) are included in Table 1 with the necessary studies.

\section{Flow measurement and evaluation}

The track on the flow capacity within DWSDN, through the measurement of the water pressure, the water level within the reservoir (Creaco et al. 2019), the track on energy consumption and the preparation of the IWA table are of important for the reduction of water loss (Fontana et al. 2018). The DWSDN shows variation in the water demand on an hourly, daily, seasonal and yearly bases.

The necessary technical infrastructure is being maintained to keep track on the water supply into the districts. SCADA has started from 2008 onward to keep track on the water input into the districts and the water levels. The following year, SCADA has started to measure the water flow through the flow meters that have been mounted to the Network. By means of SCADA, the track on the system and the prevention of overflow has been stimulated (Fig. 1).

\section{Pressure management and the realization of the district metered area}

The water pressure within the DWSDN depends on the pipeline codes, reservoir and all other pipeline levels along with the maximum water supply level and water consumptions (Choi et al. 2014). Pressure management (Adedeji et al. 2018; Fontana et al. 2018) depends on the water pressure 
Table 1 Digitization studies

\begin{tabular}{llllllll}
\hline Order No & Years & $\begin{array}{l}\text { Water breakdowns } \\
\text { (numbers) }\end{array}$ & $\begin{array}{l}\text { Authorized consump- } \\
\text { tion (numbers) }\end{array}$ & $\begin{array}{l}\text { Network valves } \\
\text { (numbers) }\end{array}$ & New lines (m) & $\begin{array}{l}\text { Network } \\
\text { renewals (m) }\end{array}$ & $\begin{array}{l}\text { Current network } \\
\text { measurements } \\
(\mathrm{m})\end{array}$ \\
\hline 1 & 2013 & 704 & 566 & 376 & 63.956 & 34.032 & 152.830 \\
2 & 2014 & 422 & 297 & 270 & 31.971 & 19.470 & 257.729 \\
3 & 2015 & 335 & 468 & 144 & 31.545 & 17.247 & 11.936 \\
4 & 2016 & 427 & 672 & 167 & 32.321 & 5.323 & 10.511 \\
5 & 2017 & 618 & 771 & 198 & 34.325 & 6.288 & 195 \\
6 & 2018 & 542 & 439 & 219 & 33.254 & 9.321 & 2.480 \\
7 & 2019 & 425 & 549 & 83 & 24.413 & 6.780 & 0 \\
Total & & 3.473 & 3.762 & 1.457 & 251.785 & 98.461 & 435.681 \\
\hline
\end{tabular}

Fig. 1 Traced works on a yearly basis

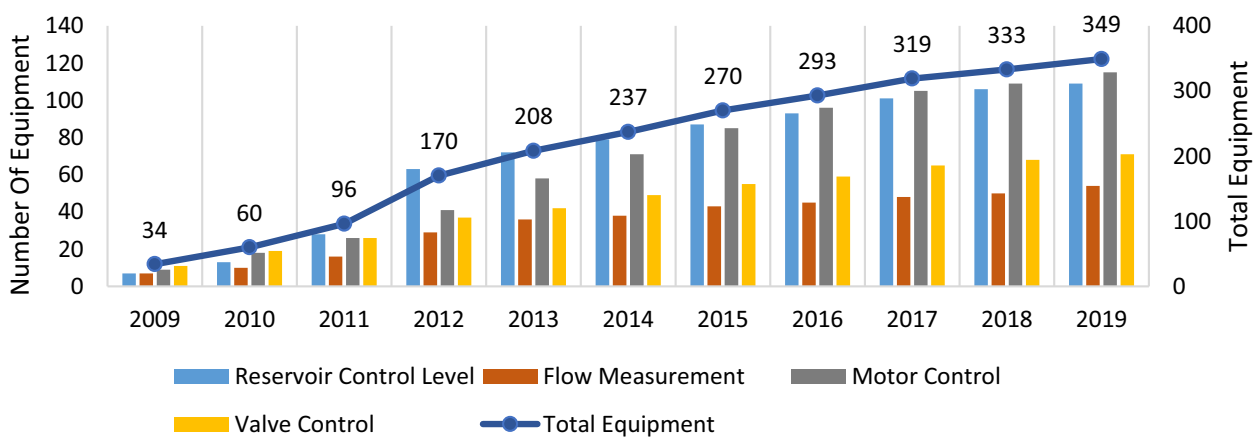

measurements in those indicated areas (Samir et al. 2017; Rizzo et al. n.d.). The water loss reduction within the DWSDN is the most (cost) effective method for the prevention of water loss (Güngör et al. 2019). In order to manage the pressure, a good analysis and controllable DMA should be separated and the necessary pressure should be controlled (Fontana et al. 2018). Pressure management means the control or pressure through check valves (Cinal 2009).

The Numbers in water loss within a large distribution network is an average of the total number (Babel et al. 2009). This approach makes it hard to reduce and have control over the water loss (Farley and Liemberger 2005). Large water networks' hydraulics have been separated from DMA in order to keep effective track on the water loss control and the small changes in the main parameters (Xin et al. 2014; Fontana et al. 2018). Generally, water pressure is being measured at the DMA entrance along with the minimum and maximum pressures (Adedeji et al. 2018). As a result, every water loss within the DMA is being measured and controlled (Lambert et al. 1999; Babel et al. 2009).

Every district that receives water should constantly be tracked and measured so that any increments in water going to that district area might have a water leak within its pipelines (Karadirek 2016). Attention to the minimum night pressure should be paid at the moment real losses within the network are being measured (Tabesh et al. 2009).

\section{Tracing water leak through acoustic leak detection}

Water leak within the network consists of three different kinds, namely inherent, visible and non-visible (Borges de Abreu and Ram'irez 2010). Inherent leakage is a small one, which is not visible and easy to determine. Non-visible leakage is not visible on the surface, but can be traced through the available technologies. It is traced through acoustic leak detection, which is being used to trace water losses that are not visible on surface and when the right equipment is not available. By using this method, water loss is being traced through a listening method, which is realized through placing acoustic leak detections on both sides of the leaked pipelines (Khulief et al. 2012). This is in order to trace the right the leaked pipeline that is under pressure. The listening performance depends on the size, figure, pipe measures and materials. The most used acoustic equipment are acoustic recorders, leakage correlators, floor microphone and sound sticks (Muhammetoğlu and Muhammetoğlu 2017).

This method has been applied to all separated DMA. The results of this method are mentioned in the section below. 


\section{Findings}

Depending on the kind of pipeline, domestic water networks are sending certain acoustic emission waves when there is a breakdown. By using the acoustic leak detection (Yang et al. 2008) it is easier to trace those emission waves. The kind of breakdown and water leak depend on the size of the pipelines, their form, the size of the breakdown, the base whereunder the breakdown occurs, the way of how the pipelines are connected and the kind of materials that have been used (valves, network etc.). Tracing breakdowns by only acoustic leak detection method will not be sufficient. Apart from the abovementioned method, it is also important to apply the pressure management and the minimum night flow (MNF) analyses.

By taking the former mentioned method into consideration, the district in the scope of this study has been divided into 132 areas. There have been build pressure chambers in the areas in order to measure the pressure more accurate. Taking these pressure chambers into hand, 19 DMA have been evaluated. Figure 2 shows the details in these areas.

The application of this method indicates that it is important to pay attention to which areas should be analyzed first and which strategies should be applied once the MNF analyses are being evaluated.

The following calculation is for determination of the relation between the percentage of water loss and the MNF.

Prior percentage $=\frac{\% \text { Loss in percentage } \times \text { MGD }}{100}=$ Leakage number

Apart from the percentage in loss and the peak in DMA, it is strongly recommended to prioritize the determination of hit peaking DMA and the number of leakage (Table 2).

As displayed in Table 2, to interpret that the numbers of water leakages are high is rather wrong when the numbers in one area are high. This along with the fact that consumption in one area might be much higher. The MNF is in this case a determined factor, which should be used along with the water loss reduction strategies to counter the numbers in leakages in those areas, where the number of water loss hits the ceiling.

In the study, an order has been made in accordance with the water leakage numbers. From the results in these numbers it is noticeable that DMA 7 should be taken on the first place. However, it is wrong to argue that the order should be made by only looking at the percentage of water loss or MNF. It should be considered to determine the leaking numbers along with all the DMA. By taking the former and the numbers in Table 2 into consideration, the ranking order will be as follows; DMA 7, DMA 9 and DMA 3. If the numbers are being determined from the water leaking numbers point of view, then the ranking order should be as follows; DMA 7, DMA 16 and DMA 13. The water leakage determination from this point of view will be a wrong starting point.

The MNF results are close to each other and by taking this occasion into consideration, DMA 7 should be determined first following DMA 9 and DMA 13. At the moment, these numbers are being used to calculate the percentage of water losses, then it can be said that DMA 9 with $62 \%$ should be determined prior to DMA 13 with a percentage of $68 \%$ water loss.

By comparing DMA 1, DMA 3 and DMA 6 among each other, it is clear that the night flow and water loss percentage in DMA 3 is bound to be the highest. From this calculation, it is clear that by using acoustic leak detection among the mentioned three districts, DMA 3 district should be prioritized. DMA 1 and DMA 6 should thereafter be taken into consideration.

Along with this determination, the ILI of every district should be calculated. From the ILI results it is clear that DMA 17 with its priority order 16 is the highest in its ILI

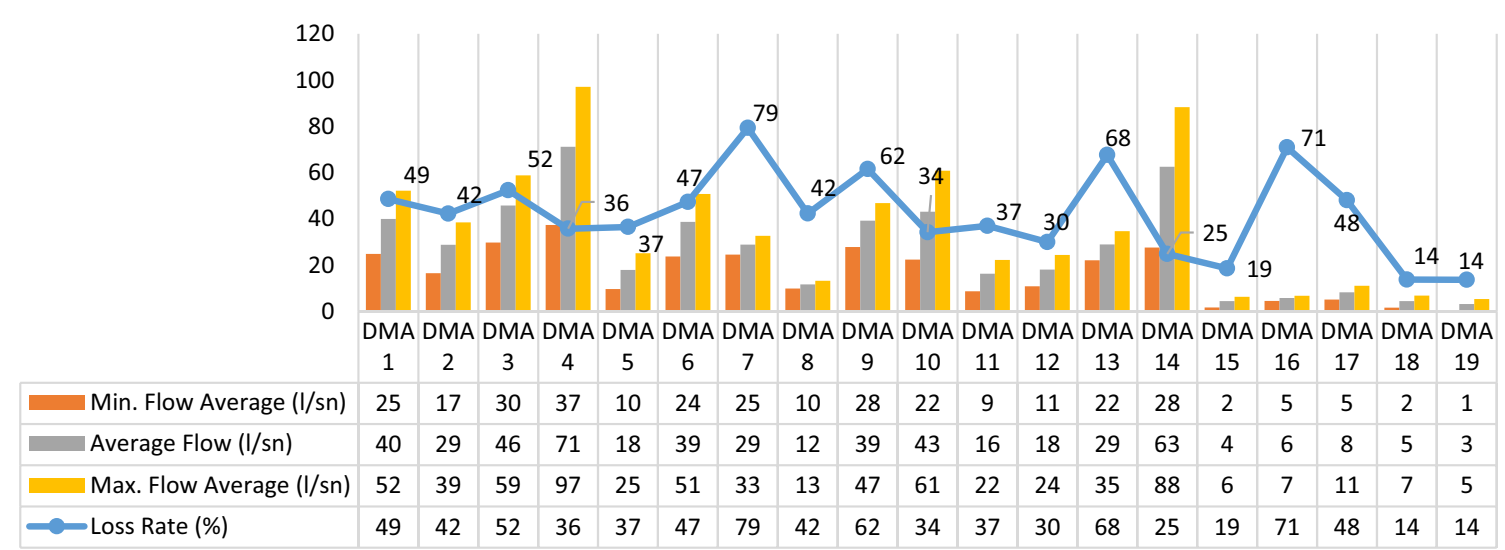

Fig. 2 DMA water loss in percentage, minimum flow rate in percentage, average of minimum flow rate, average of maximum flow rate and the average flow rate 
Table 2 The leakage determination order

\begin{tabular}{lllllll}
\hline DMA name & Water loss $(\%)$ & $\begin{array}{l}\text { Min. flow } \\
\text { rate }(1 / \mathrm{s})\end{array}$ & $\begin{array}{l}\text { Average } \\
\text { flow }(1 / \mathrm{s})\end{array}$ & Number of leaks & $\begin{array}{l}\text { Order of } \\
\text { priority }\end{array}$ & ILI \\
\hline DMA 1 & 49 & 25 & 40 & 12.10 & 6 & 5.09 \\
DMA 2 & 42 & 17 & 29 & 7.02 & 9 & 3.11 \\
DMA 3 & 52 & 30 & 46 & 15.62 & 3 & 7.01 \\
DMA 4 & 36 & 37 & 71 & 13.37 & 5 & 2.87 \\
DMA 5 & 37 & 10 & 18 & 3.54 & 12 & 3.31 \\
DMA 6 & 47 & 24 & 39 & 11.25 & 7 & 4.78 \\
DMA 7 & 79 & 25 & 29 & 19.50 & 1 & 12.82 \\
DMA 8 & 42 & 10 & 12 & 4.21 & 11 & 4.13 \\
DMA 9 & 62 & 28 & 39 & 17.16 & 2 & 8.80 \\
DMA 10 & 34 & 22 & 43 & 7.70 & 8 & 4.80 \\
DMA 11 & 37 & 9 & 16 & 3.25 & 13 & 4.40 \\
DMA 12 & 30 & 11 & 18 & 3.27 & 15 & 1.30 \\
DMA 13 & 68 & 22 & 29 & 14.97 & 4 & 20.27 \\
DMA 14 & 25 & 28 & 63 & 6.88 & 10 & 4.61 \\
DMA 15 & 19 & 2 & 4 & 0.33 & 17 & 2.09 \\
DMA 16 & 71 & 5 & 6 & 3.24 & 14 & 15.33 \\
DMA 17 & 48 & 5 & 8 & 2.49 & 16 & 21.46 \\
DMA 18 & 14 & 2 & 5 & 0.23 & 18 & 1.05 \\
DMA 19 & 14 & 1 & 3 & 0.07 & 19 & 1.10 \\
\hline
\end{tabular}

with 20.27 and DMA 13 is in the second line with an ILI of 20.27. The determination of the remaining DMAs should not only be considered with the ILI numbers, but also with the other components.

The number of leaks in the scope of this study have been tackled as follows; the non-visible leaks number has been determined first through acoustic leak method. As explained before, this method is the most effective one to trace the most non-visible leakages.

Secondly, the leaks in the remaining DMA have been determined through the same method. During the determinations in the scope of this study a lot of leakages have been tackled.

Through the acoustic leak detection, the MNF pressure management has been determined and a breakdown around 12 l/s has been tackled by preventing the leaked water from seeping further underground (Fig. 3). The former has been applied in many cases and has taken into care for water decrease within the network.

Night flow determinations in relation to the DMA have taken place and as a result, the aforementioned methods

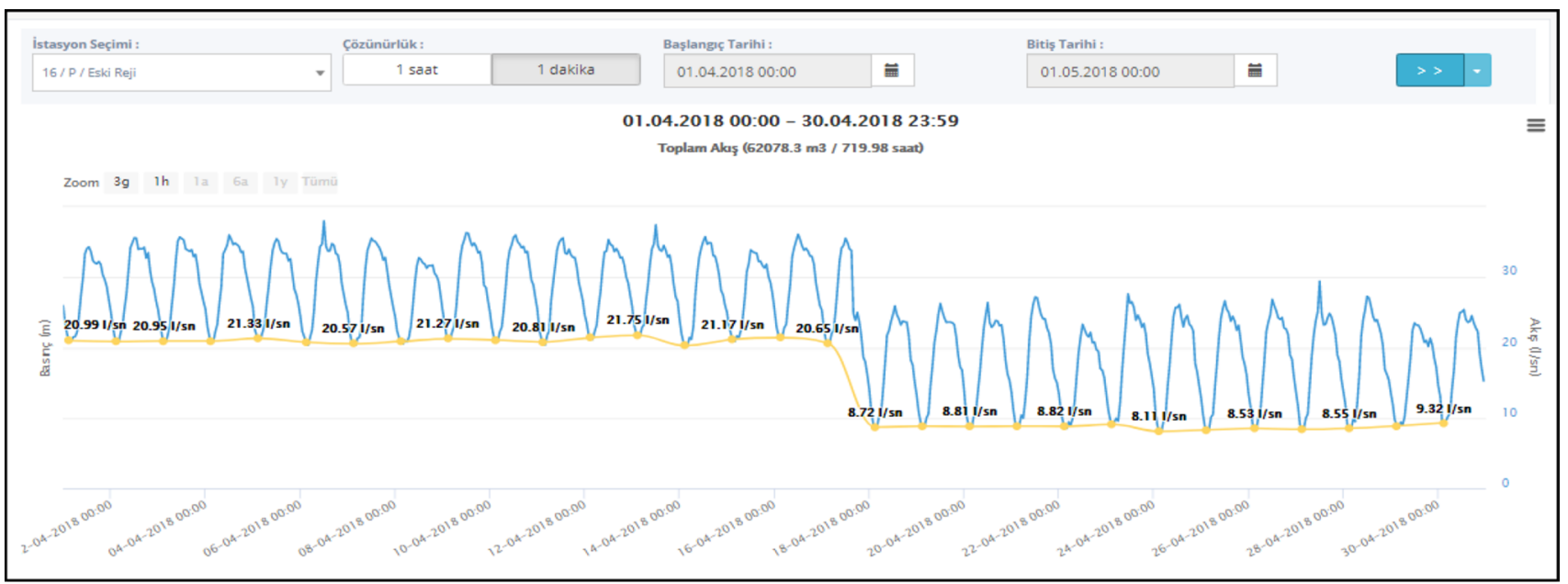

Fig. 3 Breakdown determination through Acoustic Leak Detection and the decrease of water within the Network 
have been applied and the DMA with the most leakages have been tackled (Fig. 4).

Breakdowns traced through acoustic lead detection are displayed in Fig. 3. However, Fig. 4 shows the beneficial result of traced breakdowns in the early stage. The numbers show that the water has been inserted into the network in the years 2017, 2018 and 2019 along with the percentages 5\%, $7 \%$ and $12 \%$ and costs around $12 \%, 16 \%$ and $22 \%$, respectively (Tables 3 and 4 ).

Table 5 shows the numbers in percentages for non-revenue water, where the non-revenue water is above $60 \%$. The same table reveals the numbers as a result of the applied methods. Figure 5 shows a decrease in non-revenue water from $71 \%$ to $45 \%$ and a decrease in real loss from $66 \%$ to $40 \%$ between the years 2009 and 2019 .

Those methods that have been applied in the scope of the study have taken care of drastic decrease in water loss around 26\% in the districts of Adapazar1, Erenler and Serdivan (Fig. 6).

\section{Recommendations}

In accordance with the European accession negotiations, Turkey must make an investment around 50 billion Euros. This investment is needed to supply clean and safe water. In order to meet the investment purposes, it is important to decide on the right strategies and take care of the necessary studies. Although, meeting this aim should contain studies, wherein the water loss must be tackled and this must be done by each water administration individually.

Meeting the aim to tackle the water loss to a minimum level should start by making sure that the whole organization within administration (from management until the lowest level of workers) understands the importance of the water loss reduction and the results thereof. The former responsibility should especially be transferred to the following groups.

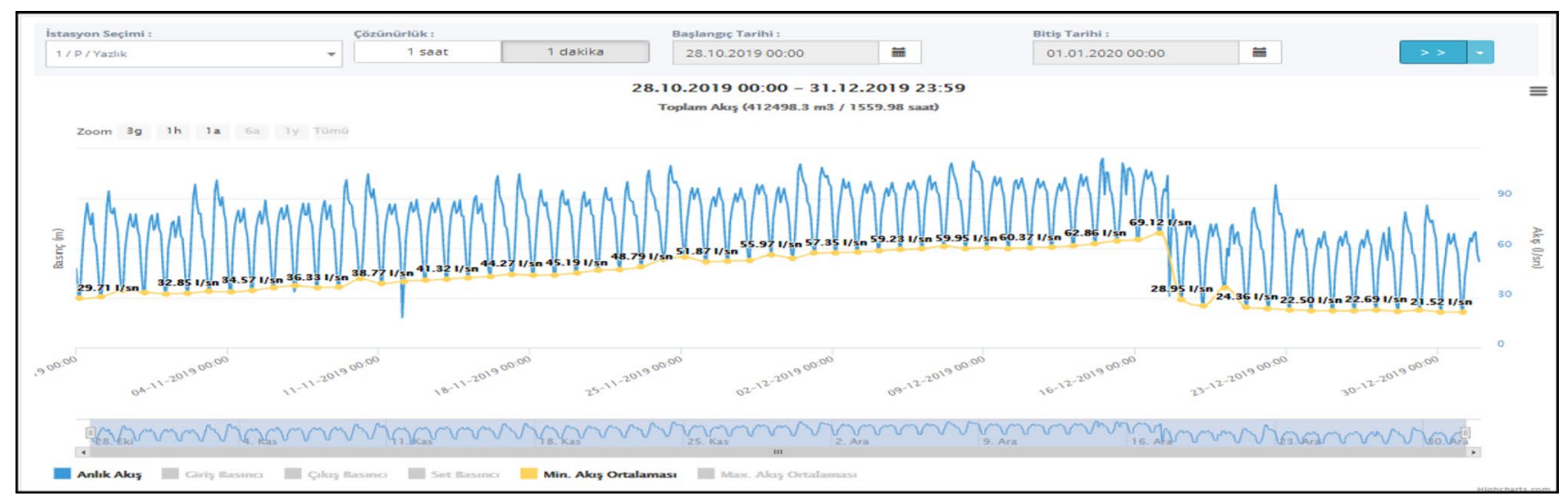

Fig. 4 Increment in MGD and the daily graphic after determination of a breakdown

Table 3 Acoustic Lead Detection numbers in years (Source: results SASKI leaking detection system)

\begin{tabular}{llllllllll}
\hline Districts & \multicolumn{1}{l}{ Years } & \multicolumn{1}{l}{ Total } \\
\cline { 2 - 9 } & 2012 & 2013 & 2014 & 2015 & 2016 & 2017 & 2018 & 2019 & \\
\hline Adapazar1 & 350 & 332 & 470 & 443 & 360 & 390 & 450 & 583 & 3378 \\
Erenler & 128 & 128 & 189 & 177 & 148 & 129 & 127 & 274 & 1300 \\
Serdivan & 240 & 198 & 282 & 266 & 252 & 192 & 225 & 260 & 1915 \\
Total & 718 & 658 & 941 & 886 & 760 & 711 & 802 & 1117 & 6593 \\
\hline
\end{tabular}

Table 4 The benefits deriving from the traced breakdowns (Source: results SASKİ SCADA system)

\begin{tabular}{|c|c|c|c|c|c|c|}
\hline \multirow{2}{*}{$\begin{array}{l}\text { DMA } \\
\text { Measured } \\
\text { district } \\
\text { areas }\end{array}$} & \multicolumn{2}{|l|}{2017} & \multicolumn{2}{|l|}{2018} & \multicolumn{2}{|l|}{2019} \\
\hline & Gained water & $\begin{array}{l}\text { Gain of water on a yearly } \\
\text { bases }\end{array}$ & Gained water & $\begin{array}{l}\text { Gained water on a yearly } \\
\text { bases }\end{array}$ & Gained water & $\begin{array}{l}\text { Gained water on a yearly } \\
\text { bases }\end{array}$ \\
\hline 13 & $298 \mathrm{~m}^{3} / \mathrm{h}$ & $2617.488 \mathrm{~m}^{3} /$ year & $410.4 \mathrm{~m}^{3} / \mathrm{h}$ & $3595.104 \mathrm{~m}^{3} /$ year & $586.4 \mathrm{~m}^{3} / \mathrm{h}$ & $5136.840 \mathrm{~m}^{3} /$ year \\
\hline
\end{tabular}


Table 5 The water supplied to the Network, the costs and the number of non-revenue water for the years between 2009 and 2019

\begin{tabular}{llllll}
\hline Years & $\begin{array}{l}\text { Supply of water } \\
\left(\mathrm{m}^{3} / \text { year }\right)\end{array}$ & Costs $\left(\mathrm{m}^{3} /\right.$ year $)$ & $\begin{array}{l}\text { Non-revenue water } \\
\left(\mathrm{m}^{3} / \text { year }\right)\end{array}$ & $\begin{array}{l}\text { Non-revenue } \\
\text { water }(\%)\end{array}$ & $\begin{array}{l}\text { Water } \\
\text { leaks } \\
(\%)\end{array}$ \\
\hline 2009 & $51,253.235$ & $14,745.610$ & $36,301.86$ & 71 & 66 \\
2010 & $54,855.301$ & $17,392.253$ & $37,219.556$ & 68 & 63 \\
2011 & $54,495.230$ & $18,199.792$ & $36,040.641$ & 66 & 61 \\
2012 & $53,151.579$ & $18,957.219$ & $33,928.959$ & 64 & 59 \\
2013 & $52,924.374$ & $20,076.479$ & $32,566.825$ & 62 & 57 \\
2014 & $49,024.036$ & $19,952.911$ & $28,791.784$ & 59 & 54 \\
2015 & $49,400.911$ & $21,326.355$ & $27,775.987$ & 56 & 51 \\
2016 & $49,760.976$ & $22,601.572$ & $26,842.982$ & 54 & 49 \\
2017 & $45,329.666$ & $21,004.396$ & $24,031.208$ & 53 & 48 \\
2018 & $44,793.101$ & $21,968.221$ & $22,517.325$ & 50 & 45 \\
2019 & $41,910.483$ & $22,670.747$ & $18,922.345$ & 45 & 40 \\
\hline
\end{tabular}

Fig. 5 The water supplied to the Network, the costs and the number of non-revenue water for the years between 2009 and 2019 (Source: results SASKI SCADA systems)

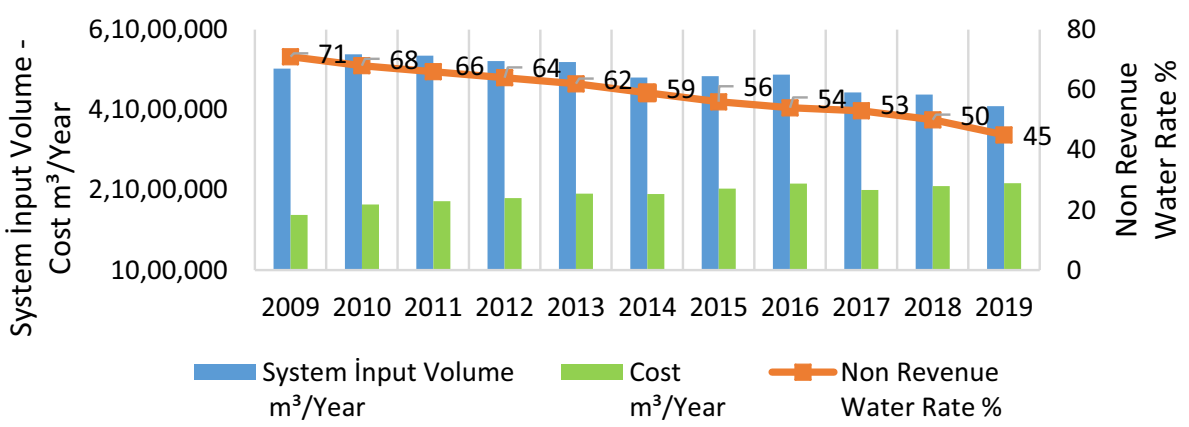

Fig. 6 Non-revenue water in three districts between 2009 and 2019 (Source: results SASKI SCADA systems)

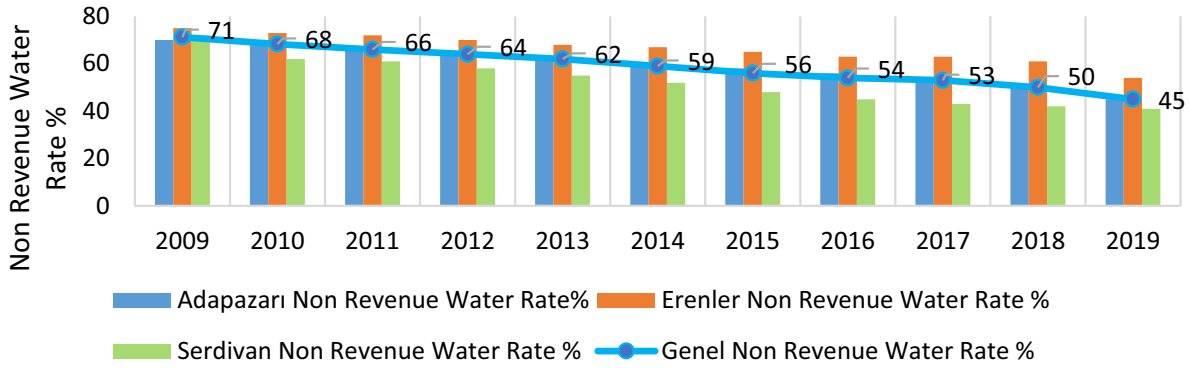

- The upper management of the water management department

- Each level of workers within the water management department

- The consumers

From this study, it has been revealed that the missing consent from the upper management and the lack of setting an appropriate budget aside results in unsuccessful strategies. If the upper management takes the risk and effort to take the necessary measurements to meet the necessary strategies then the employees on the lower level of the same department will build trust in chasing the aims. Moreover, the trust will pursue the employees to understand the breakdowns and importance in water loss, the need in tackling the breakdowns, etc.

Sakarya has developed a strategy named "Sakarya Water Loss Reduction". SASKI has started to apply this strategy by making the necessary investments and purchasing the necessary equipment to complete the DMA. In addition, the districts should be divided into several areas, the water levels within the reservoirs should be chased, all the measurements (including the night flow) should be made in real time, the input and output of the pressure reduction valves mounted to the DMAs should be measured in real time, the factors in relation to the pressure reduction must be followed and

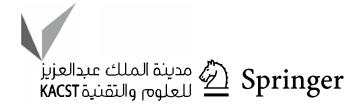


not only should the water leaks be estimated, but also the billed and consumed amount of water should be taken into consideration.

Above all, it is strongly recommended to pursue this aim to complete the strategy successfully.

Funding The author received no specific funding for this work.

\section{Compliance with ethical standards}

Conflict of interests The authors of this manuscript declare that they have no conflict of interest.

Open Access This article is licensed under a Creative Commons Attribution 4.0 International License, which permits use, sharing, adaptation, distribution and reproduction in any medium or format, as long as you give appropriate credit to the original author(s) and the source, provide a link to the Creative Commons licence, and indicate if changes were made. The images or other third party material in this article are included in the article's Creative Commons licence, unless indicated otherwise in a credit line to the material. If material is not included in the article's Creative Commons licence and your intended use is not permitted by statutory regulation or exceeds the permitted use, you will need to obtain permission directly from the copyright holder. To view a copy of this licence, visit http://creativecommons.org/licenses/by/4.0/.

\section{References}

Adedeji KB, Hamam Y, Abe BT, Abu-Mahfouz AM (2017) Leakage detection and estimation algorithm for loss reduction in water piping networks. Water 9:773. https://doi.org/10.3390/w9100773

Adedeji KB, Hamam Y, Abe BT, Abu-Mahfouz AM (2018) Pressure management strategies for water loss reduction in largescale water piping networks: a review. In: Advances in hydroinformatics. Springer, New York, pp 465-480. https://doi. org/10.1007/978-981-10-7218-5_33

Ahopelto S, Vahala R (2020) Cost-benefit analysis of leakage reduction methods in water supply networks. Water 12:195. https://doi. org/10.3390/w12010195

Alıcı OV, Özaslan K (2018) Yerel Yönetimlerde Altyapı Sistemlerinin Sayısallaştırılması Ve Su Kayıplarının Önlenmesi. Uluslar Arası Bilimsel Araştırmalar Dergisi 3(1):204-218

Babel MS, Islam MS, Gupta AD (2009) Leakage management in a lowpressure water distribution network of Bangkok. Water Sci Technol Water Supply 9(2):88. https://doi.org/10.2166/Ws.2009.088

Borges de Abreu L, Ram'irez MA (2010) Acoustic water leak detection system, the 7th international telecommunications symposium (ITS 2010), P 1

Choi YJ, Ahn JC, Im HT, Koo A (2014) Best management practices for water loss control in Seoul. Proc Eng 89:1585-1593

Cinal H (2009) Reduction of drinking water network losses by pressure management: Sakarya Case Study. Master Thesis, Sakarya University Graduate School of Natural and Applied Sciences

Creaco E, Campisano A, Fontana N, Marini G, Page PR, Walski T (2019) Real time control of water distribution networks: a stateof-the-art review. Water Res 161:517-530

Farley M, Liemberger R (2005) Developing a non-revenue water reduction strategy: planning and implementing the strategy. Water Sci Technol Water Supply 5(1):41-50
Ferrari G, Savic D (2015) Economic performance of DMAs in water distribution systems. Proc Eng 119:189-195

Fontana N, Giugni M, Marini G (2016) Experimental assessment of pressure-leakage relationship in a water distribution network. Water Sci Technol Water Supply 17(3):171. https://doi. org/10.2166/ws.2016.171

Fontana N, Giugni M, Glielmo L, Marini G, Zollo R (2018) Realtime control of pressure for leakage reduction in water distribution network: field experiments. J Water Resour Plan Manag 144(3):04017096. https://doi.org/10.1061/(ASCE)WR.19435452.0000887

García VJ, Cabrera E, Cabrera Jr E (2006) The minimum night flow method revisited. 8th Annual water distribution systems analysis symposium, Cincinnati, Ohio, USA, 27-30 August 2006

Gomes R, Marques AS, Sousa J (2012a) Identification of the optimal entry points at district metered areas and implementation of pressure management. Urban Water J 9(6):365-384

Gomes R, Sá Marques A, Sousa J (2012b) Decision support system to divide a large network into suitable district metered areas. Water Sci Technol 65:1667-1675

Güngör M, Ufuk Y, Cantürk Ü, Fırat M (2019) Increasing performance of water distribution network by using pressure management and database integration. J Pipeline Syst Eng Pract 10(2):04019003. https://doi.org/10.1061/(ASCE)PS.1949-1204.0000367

Hussein M, Yoneda K, Othman N, Zaki ZM, Yusof MHM (2017) Effects of number of connections and pipe length to the water losses in Melaka. Jurnal Teknologi 79(3):45-59

Kanakoudis VK, Tolikas DK (2001) The role of leaks and breaks in water networks: technical and economical solutions. J Water Supply Res Technol AQUA 50(5):301-311

Kanakoudis V, Tsitsifli S (2009) Evaluatıng the performance of an urban water distribution network: tips and tricks for toubleshooting. Ewra Seventh International conference water resources conservancy and risk reduction under climatic uncertainty Limassol, Cyprus, 25-27 June 2009

Kanakoudis V, Tsitsifli S, Kouziakis C, Lappos S (2015) Defining the level of the Non-Revenue Water in Kozani, Greece: is it a typical case? J Desalin Water Treat 54(8):934119. https://doi. org/10.1080/19443994.2014.934119

Kara S, Karadirek IE, Muhammetoglu A, Muhammetoglu H (2015) Real time monitoring and control in water distribution systems for improving operational efficiency. Desalin Water Treat. https ://doi.org/10.1080/19443994.2015.1069224

Karadirek IE (2016) Urban water losses management in Turkey: the legislation and challenges. Anadolu Univ J Sci Technol A Appl Sci Eng 17(3):572-584. https://doi.org/10.18038/btda.67184

Keskin ME, Yılmaz AG (2005) Altyapı Şebekelerinin Yönetiminde Kent Bilgi Sisteminin Önemi. https://www.imo.org.tr/resimler/ ekutuphane/pdf/10023.Pdf

Khulief YA, Khalifa A, Ben Mansour R, Habib MA (2012) Acoustic detections of leaks in water pipelines using meausurements İnside pipe. J Pipeline Syst Eng Pract 3(2):47-54

Lambert A, Hirner W (2000) Losses from Water Supply Systems: standard terminology and recommended performance measures. Blue Pages 10:320-338

Lambert AO, Brown TG, Takizawa M, Weimer D (1999) A review of performance indicators for real losses from water supply systems. J Water Supply Res Technol AQUA 48(6):227-237

Muhammetoğlu H, Muhammetoğlu A (2017) İçme Suyu Temin Ve Dağıtım Sistemlerindeki Su Kayıplarının Kontrolü El Kitabı, Temmuz

Muhammetoğlu A, Muhammetoğlu H, Adıgüzel A, İritaş Ö, Karaaslan Y (2018) Management of water losses in water supply and distribution networks in Turkey. Turk J Water Sci Manag 2(1):58-75. https://doi.org/10.31807/Tjwsm.354298 
Ociepa E, Mrowiec M, Deska I (2019) Analysis of water losses and assessment of initiatives aimed at their reduction in selected water supply systems. Water 11:1037. https://doi.org/10.3390/w1105 1037

Özdemir Ö (2018) Water leakage management by district metered areas at water distribution networks. Environ Monit Assess 190:182. https://doi.org/10.1007/s10661-018-6559-9

Richards GL, Johnson MC, Barfuss SL (2010) Apparent losses caused by water meter inaccuracies at ultralow flows. J Am Water Works Assoc 102(5):123-132. https://doi.org/10.1002/j.1551-8833.2010. tb10115.x

Rizzo A, Vermersch M, John GS, Micallef G, Riolo S, Pace R (n.d.) Apparent water loss control: the way forward. https://arivalves. com/index.php/watersupply-library/2013-06-23-13-38-26

Samir N, Kansoh R, Elbarki W, Fleifle A (2017) Pressure control for minimizing leakage in water distribution systems. Alex Eng J 56:601-612

Tabesh M. · Yekta A. H. A. and Burrows R., An integrated model to evaluate losses in water distribution systems, Water Resour
Manag (2009) 23:477-492 DOI https://doi.org/10.1007/s1126 9-008-9284-2

Washali TA, Sharma S, Lupoja R, Nozaily FA, Haidera M, Kennedy M (2020) Assessment of water losses in distribution networks: methods, applications, uncertainties, and implications in intermittent supply. Resour Conserv Recycling 152:104515

Xin K, Tao T, Lu Y, Xiong X, Li F (2014) Apparent losses analysis in district metered areas of water distribution systems. Water Resour Manag 28:683-696. https://doi.org/10.1007/s11269-013-0508-8

Yang J, Wen Y, Li P (2008) Leak acoustic detection in water distribution pipelines. Proceedings of the 7th World Congress on intelligent control and automation, Chongqing, China, 25-27 June 2008

Publisher's note Springer Nature remains neutral with regard to jurisdictional claims in published maps and institutional affiliations. 